\title{
Effect of empagliflozin monotherapy on postprandial glucose and 24-hour glucose variability in Japanese patients with type 2 diabetes mellitus: a randomized, double-blind, placebo-controlled, 4-week study
}

Rimei Nishimura', Yuko Tanaka ${ }^{2 *}$, Kazuki Koiwai ${ }^{2}$, Kohei Inoue ${ }^{3}$, Thomas Hach ${ }^{4}$, Afshin Salsali ${ }^{5}$, Søren S Lund ${ }^{4}$ and Uli C Broedl ${ }^{4}$

\begin{abstract}
Background: This study evaluated the effect of empagliflozin on postprandial glucose (PPG) and 24-hour glucose variability in Japanese patients with type 2 diabetes mellitus (T2DM).

Methods: Patients ( $\mathrm{N}=60$; baseline mean [SD] HbA1c 7.91 [0.80]\%; body mass index $24.3[3.2] \mathrm{kg} / \mathrm{m}^{2}$ ) were randomized to receive empagliflozin $10 \mathrm{mg}(n=20)$, empagliflozin $25 \mathrm{mg}(n=19)$ or placebo $(n=21)$ once daily as monotherapy for 28 days. A meal tolerance test and continuous glucose monitoring (CGM) for 24 hours were performed at baseline and on days 1 and 28. The primary endpoint was change from baseline in area under the glucose concentration-time curve 3 hours after breakfast (AUC ${ }_{1-4 h}$ for PPG) at day 28.

Results: Adjusted mean (95\%) differences versus placebo in changes from baseline in AUC 1 -4h for PPG at day 1 were $-97.1(-126.5,-67.8) \mathrm{mg} \cdot \mathrm{h} / \mathrm{dl}$ with empagliflozin $10 \mathrm{mg}$ and $-91.6(-120.4,-62.8) \mathrm{mg} \cdot \mathrm{h} / \mathrm{dl}$ with empagliflozin $25 \mathrm{mg}$ (both $\mathrm{p}<0.001$ versus placebo) and at day 28 were $-85.5(-126.0,-45.0) \mathrm{mg} \cdot \mathrm{h} / \mathrm{dl}$ with empagliflozin $10 \mathrm{mg}$ and $-104.9(-144.8,-65.0) \mathrm{mg} \cdot \mathrm{h} / \mathrm{dl}$ with empagliflozin $25 \mathrm{mg}$ (both $\mathrm{p}<0.001$ versus placebo). Adjusted mean $(95 \% \mathrm{Cl})$ differences versus placebo in change from baseline in 24-hour mean glucose (CGM) at day 1 were $-20.8(-27.0,-14.7) \mathrm{mg} / \mathrm{dl}$ with empagliflozin $10 \mathrm{mg}$ and $-23.9(-30.0,-17.9) \mathrm{mg} / \mathrm{dl}$ with empagliflozin $25 \mathrm{mg}$ (both $\mathrm{p}<0.001$ versus placebo) and at day 28 were $-24.5(-35.4,-13.6) \mathrm{mg} / \mathrm{dl}$ with empagliflozin $10 \mathrm{mg}$ and $-31.7(-42.5,-20.9) \mathrm{mg} / \mathrm{dl}$ with empagliflozin $25 \mathrm{mg}$ (both $p<0.001$ versus placebo). Changes from baseline in mean amplitude of glucose excursions (MAGE; CGM) were not significantly different with either empagliflozin dose versus placebo at either timepoint. Curves of mean glucose (CGM) did not change between baseline and day 1 or 28 with placebo, but shifted downward with empagliflozin. Percentage of time with glucose $\geq 70$ to $<180 \mathrm{mg} / \mathrm{dl}$ increased from $52.0 \%$ at baseline to $77.0 \%$ at day 28 with empagliflozin $10 \mathrm{mg}$ and from $55.0 \%$ to $81.1 \%$ with empagliflozin $25 \mathrm{mg}$, without increasing time spent with hypoglycemia.
\end{abstract}

Conclusion: Empagliflozin for 28 days reduced PPG from the first day and improved daily blood glucose control in Japanese patients with T2DM.

Trial registration: Clinicaltrials.gov NCT01947855

Keywords: SGLT2 inhibitor, Continuous glucose monitoring, CGM

\footnotetext{
* Correspondence: yuko.tanaka@boehringer-ingelheim.com

${ }^{2}$ Nippon Boehringer Ingelheim Co. Ltd, Osaki 2-1-1, ThinkPark Tower, Tokyo

141-6017, Japan

Full list of author information is available at the end of the article
} 


\section{Background}

The prevalence of diabetes in Japan is increasing [1]. Cardiovascular and all-cause mortality are increased in Japanese patients with diabetes [2].

Postprandial hyperglycemia is common in patients with type 2 diabetes (T2DM) [3,4]. Control of postprandial glucose (PPG) helps patients to achieve HbA1c goals $[5,6]$, and some guidelines for the management of T2DM provide specific targets for PPG [7-9]. Postprandial hyperglycemia is an independent risk factor for cardiovascular disease $[10,11]$, possibly due to the oxidative stress, endothelial dysfunction and overexpression of adhesion molecules triggered by acute hyperglycemia and glucose fluctuations [12,13]. Daily glucose fluctuations may also increase the risk of microvascular and macrovascular complications associated with T2DM $[14,15]$ while severe hypoglycemia is associated with increased mortality $[16,17]$.

Inhibition of the sodium glucose cotransporter 2 (SGLT2), located in the proximal tubule, reduces renal glucose reabsorption, leading to increased urinary glucose excretion and reduced hyperglycemia in patients with T2DM [18,19]. Empagliflozin is a selective and potent SGLT2 inhibitor [20]. In international Phase III trials in patients with T2DM, 24 weeks' treatment with empagliflozin given as monotherapy or as add-on therapy for 24 weeks was well tolerated and significantly reduced glycated hemoglobin (HbA1c), fasting plasma glucose (FPG), body weight and systolic blood pressure (SBP) versus placebo [21-24]. In Japanese patients with T2DM, empagliflozin monotherapy for 52 weeks led to sustained reductions in HbA1c, FPG, body weight and SBP $[25,26]$. The effect of empagliflozin on 24-hour glycemic variability in patients with T2DM has not been assessed.

This study was conducted to evaluate the effect of empagliflozin $10 \mathrm{mg}$ and $25 \mathrm{mg}$ once daily as monotherapy for 28 days on PPG and 24-hour glycemic variability in Japanese patients with T2DM.

\section{Methods}

This was a randomized, double-blind, placebo-controlled, parallel-group study conducted at two sites in Japan. The clinical trial protocol was approved by the Institutional Review Boards of the participating centers, and complied with the Declaration of Helsinki in accordance with the International Conference on Harmonisation Harmonised Tripartite Guideline for Good Clinical Practice. All patients provided written informed consent. The trial was registered with ClinicalTrials.gov (NCT01947855).

\section{Patients}

Japanese patients with T2DM aged $\geq 20$ and $\leq 74$ years, with a body mass index (BMI) $\leq 40 \mathrm{~kg} / \mathrm{m}^{2}$, who were on a diet and exercise regimen and were drug-naïve (no anti-diabetes agents for $\geq 12$ weeks prior to consent) or treated with 1 oral anti-diabetes agent (except a sulfonylurea at $>$ half maximum approved daily dose, or a thiazolidinedione) at an unchanged dose for $\geq 12$ weeks prior to consent, were eligible for inclusion. At screening, drug-naïve patients were required to have $\mathrm{HbA} 1 \mathrm{c} \geq 7 \%$ and $\leq 10 \%$ and patients treated with 1 oral anti-diabetes agent were required to have $\mathrm{HbA} 1 \mathrm{c} \geq 7 \%$ and $\leq 9.5 \%$. All patients were required to have $\mathrm{HbA} 1 \mathrm{c} \geq 7 \%$ to $\leq 10 \%$ at the start of the placebo runin period.

Exclusion criteria included uncontrolled hyperglycemia (glucose level $>240 \mathrm{mg} / \mathrm{dl}$ ) after an overnight fast confirmed by a second measurement; acute coronary syndrome, stroke or transient ischemic attack $\leq 20$ weeks prior to randomization; indication of liver disease (alanine aminotransferase, alkaline aminotransferase or alkaline phosphatase levels $>3$ times the upper limit of normal during screening, washout or run-in); impaired renal function (estimated glomerular filtration rate [eGFR] $<60 \mathrm{ml} / \mathrm{min} /$ $1.73 \mathrm{~m}^{2}$ according to Japanese estimation equation [27]) during screening, washout or run-in; gastrointestinal surgeries that induce chronic malabsorption; treatment with insulin, glucagon-like peptide-1 (GLP-1) analogues, sulfonylurea at $>$ half the daily maximum approved dose or thiazolidinedione within 12 weeks prior to consent; treatment with antiobesity drugs within 12 weeks prior to consent; use of any treatment at screening leading to unstable body weight; treatment with systemic steroids at time of consent; change in dosage of thyroid hormones within 6 weeks prior to consent; alcohol or drug abuse within 12 weeks of consent; investigational drug intake in another trial within 30 days of consent.

\section{Randomization and interventions}

All patients underwent a 2-week, open-label, placebo runin period. Patients pre-treated with an oral anti-diabetes agent underwent a 2-week washout period prior to the placebo run-in. Following the run-in period, eligible patients were randomized (in a 1:1:1 ratio) to receive empagliflozin $10 \mathrm{mg}$, empagliflozin $25 \mathrm{mg}$, or placebo for 28 days. Patients were monitored at the trial site from days -2 to 2 and days 27 to 29. Blinded 24-hour continuous glucose monitoring (CGM) and a meal tolerance test (MTT) were performed at day -1 , day 1 (of treatment) and day 28 (Figure 1). Patients were assigned to test meals providing 1440,1600 , or $1840 \mathrm{kcal} /$ day, based on patient's standard weight (Additional file 1: Table S1). Test meals contained 50-60\% carbohydrate, $15-21 \%$ protein, and $21-35 \%$ fat (Additional file 1: Table S1). Plasma glucose profiles were determined at the timepoints shown in Figure 1.

\section{Endpoints}

The primary endpoint was the change from baseline (day -1$)$ in the area under the glucose concentration- 


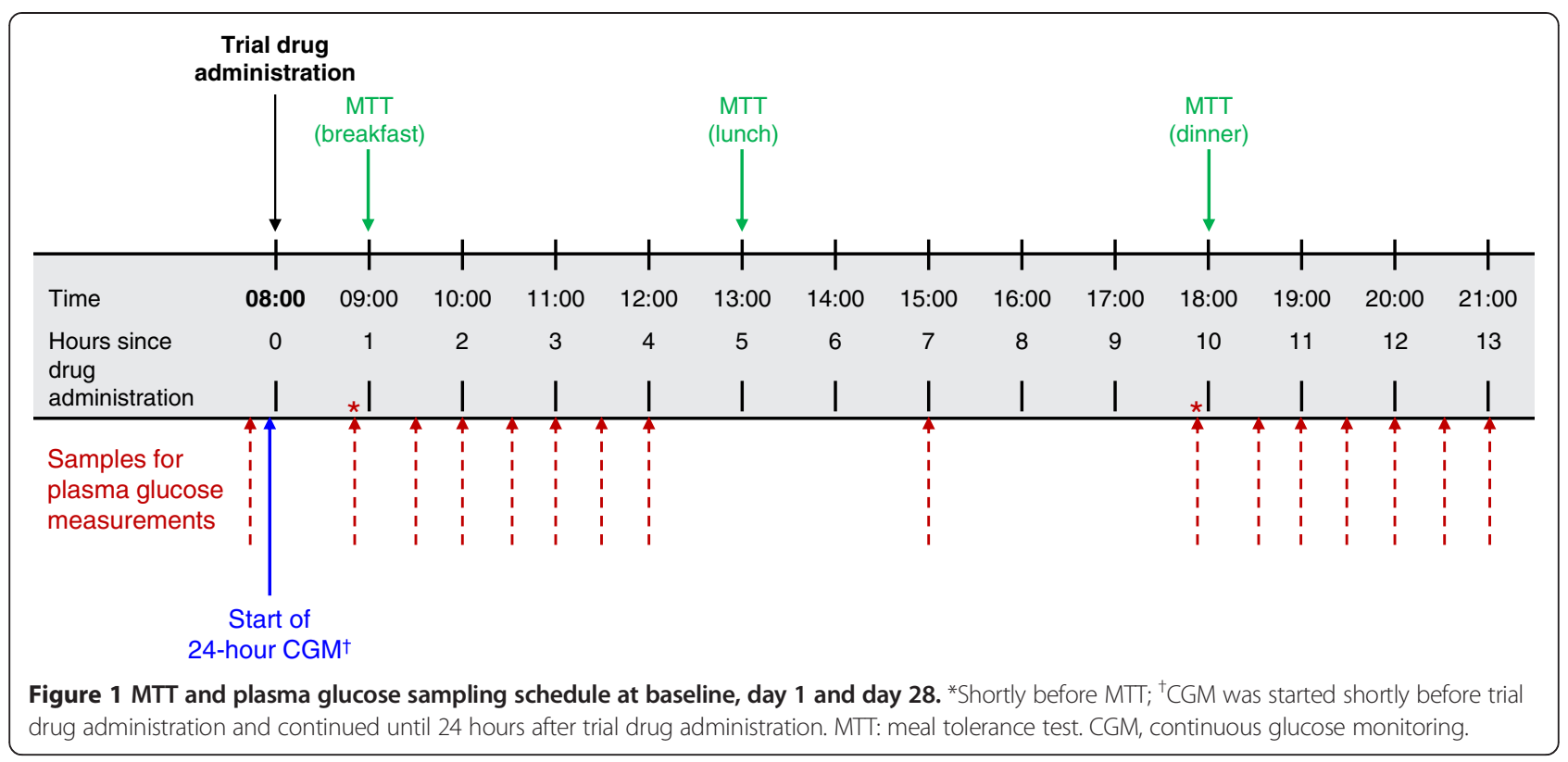

time curve 3 hours after breakfast ( $\mathrm{AUC}_{1-4 \mathrm{~h}}$ for PPG) at day 28. Other efficacy endpoints were change from baseline in $\mathrm{AUC}_{1-4 \mathrm{~h}}$ for PPG at day 1, change from baseline in AUC of glucose 3 hours after dinner $\left(\mathrm{AUC}_{10-13 \mathrm{~h}}\right.$ for PPG) at day 1 and day 28, change from baseline in 2-hour PPG after each meal (breakfast, lunch, dinner) at day 1 and day 28 , change from baseline in FPG at day 2 and 29 and change from baseline in $\mathrm{AUC}_{1-4 \mathrm{~h}}$ and $\mathrm{AUC}_{10-13 \mathrm{~h}}$ for postprandial insulin at day 1 and day 28. Endpoints measured from CGM at day 1 and day 28 were changes from baseline in 24-hour mean glucose, mean amplitude of glucose excursions (MAGE) [28] and the percentage of time with glucose $\geq 180 \mathrm{mg} / \mathrm{dl}, \geq 70$ to $<180 \mathrm{mg} / \mathrm{dl}$ and $<70 \mathrm{mg} / \mathrm{dl}$ per day. MAGE was calculated as the arithmetic mean difference between consecutive blood glucose peaks (between meals) and nadirs (between the peaks) when differences were $>1$ standard deviation of the mean glucose value in the same 24hour period. Change from baseline in HbA1c was measured at day 29. Change from baseline in urinary excretion of 8 -iso-prostaglandin F2 $\alpha$ (8-iso-PGF2 $\alpha$; a marker of oxidative stress) in the fasting state and in the 24 hours after study drug administration was measured at day 28 . Safety endpoints included changes in vital signs, weight, and clinical laboratory parameters, and adverse events (AEs; preferred terms coded according to the Medical Dictionary for Drug Regulatory Activities [MedDRA] version 16.1). AEs included all events with an onset after the first dose and up to 7 days after the last dose of study medication. Confirmed hypoglycemic AEs were defined as AEs with plasma glucose $\leq 70 \mathrm{mg} / \mathrm{dL}$ and/or requiring assistance. Events consistent with urinary tract infection (UTI), genital infection, and volume depletion were identified using prospectively defined search categories using 77,89 and 8 preferred terms, respectively.

\section{Statistical analysis}

Efficacy analyses were performed on the full analysis set (FAS) which included patients treated with $\geq 1$ dose of study drug who had a baseline value for $\mathrm{AUC}_{1-4 \mathrm{~h}}$ for PPG. Safety was assessed in the treated set (patients treated with $\geq 1$ dose of study drug).

The primary endpoint was analyzed using an analysis of covariance (ANCOVA) model, with treatment, baseline eGFR and number of previous anti-diabetes medications as fixed effects and baseline HbA1c and baseline $\mathrm{AUC}_{1-4 \mathrm{~h}}$ for PPG as linear covariates. Missing data were not imputed. In the hierarchical testing procedure, the superiority of empagliflozin $25 \mathrm{mg}$ versus placebo was to be tested first, followed by empagliflozin $10 \mathrm{mg}$ versus placebo if the first test was significant. Other efficacy endpoints were analyzed using the ANCOVA model described for the primary endpoint, with the baseline value for the endpoint in question as an additional linear covariate.

Safety analyses were descriptive, except for changes in lipid parameters, free fatty acids and blood ketone bodies, which were analyzed using ANCOVA.

Postprandial insulin data and triglyceride data were log-transformed prior to analysis.

A sample size of 20 patients per treatment group was required to provide power of $95 \%$ for the pair-wise comparison and an overall power of $\geq 90 \%$ to detect a $150 \mathrm{~h} \cdot \mathrm{mg} / \mathrm{dl}$ treatment difference in $\mathrm{AUC}_{1-4 \mathrm{~h}}$ for $\mathrm{PPG}$ for each 
empagliflozin dose compared to placebo, assuming a standard deviation of $120 \mathrm{~h} \cdot \mathrm{mg} / \mathrm{dl}$ and a dropout rate of 2 patients per group.

\section{Results}

\section{Patients}

Of 78 patients screened, 60 patients were randomized and treated and comprised the FAS. One patient in the placebo group discontinued prematurely. Baseline characteristics were balanced across treatment groups (Table 1).

\section{Efficacy}

Compared with placebo, empagliflozin $10 \mathrm{mg}$ and $25 \mathrm{mg}$ led to significant reductions from baseline in $\mathrm{AUC}_{1-4 \mathrm{~h}}$ for PPG at day 1 and at day 28 (Figure 2A) and in $\mathrm{AUC}_{10-13 \mathrm{~h}}$ for PPG at day 1 and at day 28 (Figure 2B). Reductions in $\mathrm{AUC}_{1-4 \mathrm{~h}}$ and $\mathrm{AUC}_{10-13 \mathrm{~h}}$ for PPG at day 28 compared with placebo were greater with empagliflozin $25 \mathrm{mg}$ than empagliflozin $10 \mathrm{mg}$ (No statistical tests were performed on the differences between the empagliflozin $10 \mathrm{mg}$ and $25 \mathrm{mg}$ groups). Empagliflozin $10 \mathrm{mg}$ and $25 \mathrm{mg}$ reduced $\mathrm{AUC}_{1-4 \mathrm{~h}}$ and $\mathrm{AUC}_{10-13 \mathrm{~h}}$ for post-prandial insulin at day 1 and day 28, but changes in $\mathrm{AUC}_{1-4 \mathrm{~h}}$ with empagliflozin $10 \mathrm{mg}$ at day 28 were not significantly different to placebo (Table 2).

Changes from baseline in 2-hour PPG were significantly greater with empagliflozin $10 \mathrm{mg}$ and $25 \mathrm{mg}$ compared with placebo after breakfast at day 1 and day 28 (Figure 2C). Changes from baseline in 2-hour PPG after lunch were significantly greater with empagliflozin $10 \mathrm{mg}$ compared with placebo at day 1 , but did not reach significance versus placebo with empagliflozin $10 \mathrm{mg}$ at day 28 or with empagliflozin $25 \mathrm{mg}$ at day 1 or day 28 (Figure 2C). Changes from baseline in 2-hour PPG after dinner were significantly different with empagliflozin $10 \mathrm{mg}$ and empagliflozin $25 \mathrm{mg}$ compared with placebo at day 28 but not at day 1 (Figure $2 \mathrm{C}$ ).

Empagliflozin $10 \mathrm{mg}$ and $25 \mathrm{mg}$ led to significant reductions from baseline in FPG compared with placebo at day 2 and at day 29 (Figure 3). Reductions from baseline in FPG at day 29 compared with placebo were greater with empagliflozin $25 \mathrm{mg}$ than empagliflozin $10 \mathrm{mg}$.

Empagliflozin $10 \mathrm{mg}$ and $25 \mathrm{mg}$ led to significant reductions from baseline in 24-hour mean glucose compared with placebo at day 1 and at day 28 (Figure 4). Reductions from baseline in 24-hour mean glucose compared with placebo at day 28 were greater with empagliflozin $25 \mathrm{mg}$ than empagliflozin $10 \mathrm{mg}$. Mean glucose levels over 24 hours by CGM at baseline, day 1 and day 28 are shown in Figure 5 . A reduction from baseline (downward shift) in mean glucose levels at all timepoints over 24 hours was evident from day 1 with empagliflozin, and reductions from baseline

Table 1 Patient demographics and baseline characteristics (full analysis set)

\begin{tabular}{|c|c|c|c|}
\hline & Placebo & $\begin{array}{l}\text { Empagliflozin } \\
10 \mathrm{mg}\end{array}$ & $\begin{array}{l}\text { Empagliflozin } \\
25 \mathrm{mg}\end{array}$ \\
\hline $\mathrm{N}$ & 21 & 20 & 19 \\
\hline Male & $17(81.0)$ & $14(70.0)$ & $16(84.2)$ \\
\hline Age (years) & $60.7(10.8)$ & $64.8(5.9)$ & $62.6(7.8)$ \\
\hline \multicolumn{4}{|l|}{ Time since diagnosis of type 2 diabetes } \\
\hline$\leq 5$ years & $9(42.9)$ & $4(20.0)$ & $5(26.3)$ \\
\hline$>5$ to 10 years & $9(42.9)$ & $8(40.0)$ & $7(36.8)$ \\
\hline$>10$ years & $3(14.3)$ & $8(40.0)$ & $7(36.8)$ \\
\hline \multicolumn{4}{|l|}{ Number of anti-diabetes medications } \\
\hline 0 & $18(85.7)$ & $16(80.0)$ & $17(89.5)$ \\
\hline 1 & $3(14.3)$ & $4(20.0)$ & $2(10.5)$ \\
\hline Body weight (kg) & $67.7(10.0)$ & $63.5(10.6)$ & $65.9(12.1)$ \\
\hline Body mass index $\left(\mathrm{kg} / \mathrm{m}^{2}\right)$ & $24.9(2.8)$ & $24.1(3.7)$ & $24.0(3.2)$ \\
\hline $\mathrm{HbA1c}(\%)$ & $8.00(0.82)$ & $7.99(0.83)$ & $7.73(0.75)$ \\
\hline Fasting plasma glucose $(\mathrm{mg} / \mathrm{dl})^{*}$ & $154.5(19.8)$ & $151.0(21.6)$ & $151.9(23.3)$ \\
\hline$A \cup C_{1-4 h}$ for postprandial glucose $(\mathrm{mg} \cdot \mathrm{h} / \mathrm{dl})$ & $682.8(91.2)$ & $680.4(92.2)$ & $658.1(116.2)$ \\
\hline 24-hour mean glucose (mg/dl) & $184.1(30.5)$ & $181.3(25.9)$ & $178.4(33.4)$ \\
\hline Mean amplitude of glucose excursions, MAGE (mg/dl) & $91.4(26.4)$ & $94.1(18.5)$ & $89.1(29.7)$ \\
\hline Estimated glomerular filtration rate $\left(\mathrm{ml} / \mathrm{min} / 1.73 \mathrm{~m}^{2}\right)$ (Japanese estimation equation [27]) & $82.6(12.8)$ & $76.5(11.1)$ & $80.7(9.3)$ \\
\hline Systolic blood pressure $(\mathrm{mmHg})^{*}$ & $119.8(11.5)$ & $119.1(15.9)$ & $124.0(11.6)$ \\
\hline Diastolic blood pressure $(\mathrm{mmHg})^{*}$ & $71.8(7.7)$ & $70.7(10.7)$ & $74.7(8.0)$ \\
\hline
\end{tabular}

Data are $\mathrm{n}(\%)$ or mean (standard deviation). *Baseline for these parameters is day 1. 


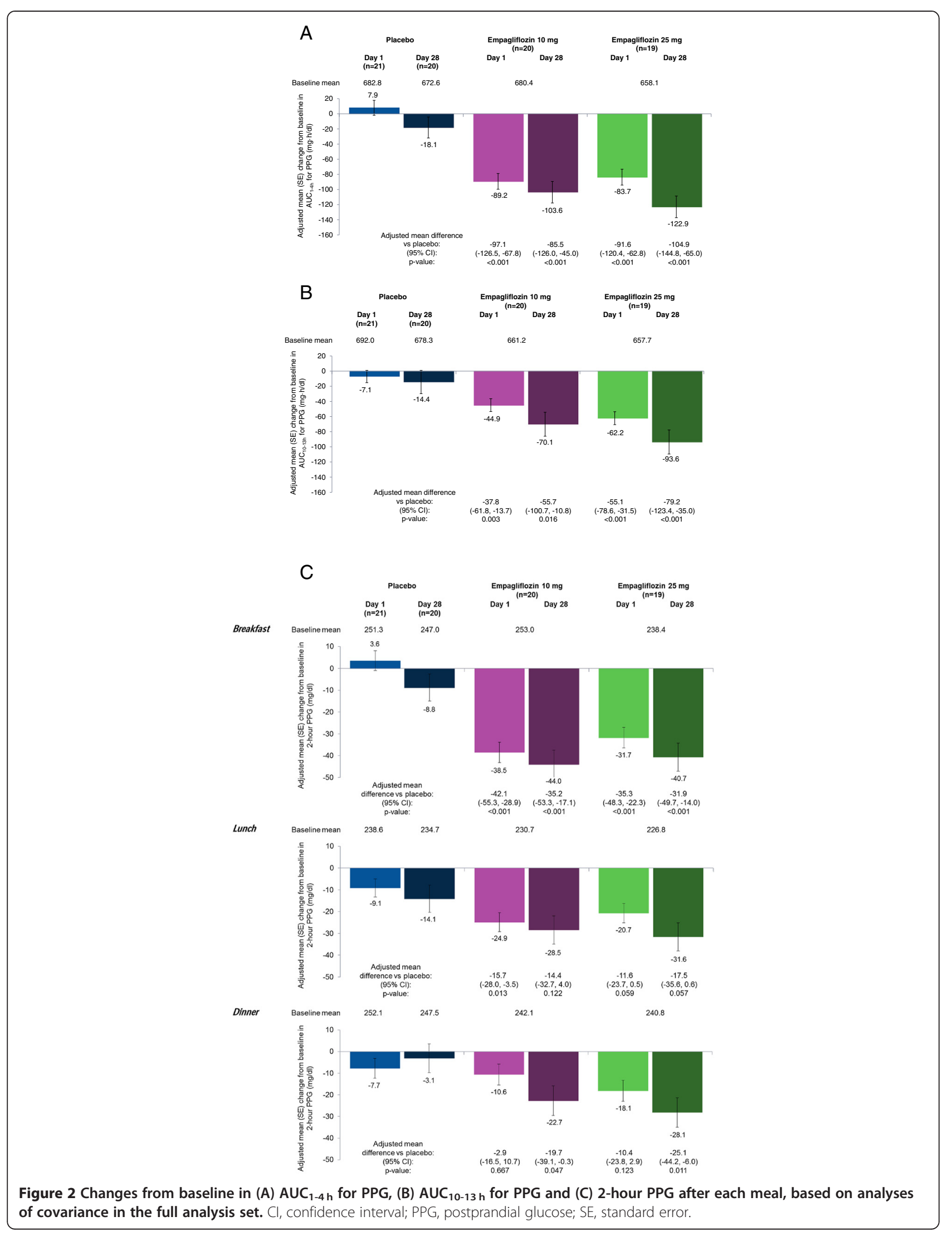


Table 2 Changes in postprandial insulin after breakfast and dinner at day 1 and day 28

\begin{tabular}{|c|c|c|c|}
\hline & Placebo $(n=20)$ & Empagliflozin 10 mg $(n=20)$ & Empagliflozin $25 \mathrm{mg}(\mathrm{n}=19)$ \\
\hline \multicolumn{4}{|l|}{$\mathrm{AUC}_{1-4 \mathrm{~h}}$ for postprandial insulin, $\mu \mathrm{IU} \cdot \mathrm{h} / \mathrm{ml}$} \\
\hline Baseline & $66.4(63.5)^{*}$ & $58.9(55.6)$ & $65.3(46.2)$ \\
\hline Relative change from baseline at day 1 & $1.2(1.1,1.3)$ & $1.0(0.9,1.1)$ & $1.0(0.9,1.0)$ \\
\hline Difference vs placebo (95\% Cl) & & $0.8(0.7,0.9)$ & $0.8(0.7,0.9)$ \\
\hline$p$-value & & $<0.001$ & $<0.001$ \\
\hline Relative change from baseline at day 28 & $1.0(0.9,1.1)$ & $0.9(0.8,0.9)$ & $0.8(0.7,0.9)$ \\
\hline Difference vs placebo (95\% Cl) & & $0.9(0.8,1.0)$ & $0.8(0.7,0.9)$ \\
\hline$p$-value & & 0.074 & 0.002 \\
\hline \multicolumn{4}{|c|}{$A U C_{10-13 h}$ for postprandial insulin, $\mu \mathrm{lU} \cdot \mathrm{h} / \mathrm{ml}$} \\
\hline Baseline & $73.8(56.6) \dagger$ & $60.7(60.5)$ & $70.0(53.7)$ \\
\hline Relative change from baseline at day 1 & $1.1(1.0,1.2)$ & $0.9(0.8,1.0)$ & $0.9(0.8,0.9)$ \\
\hline Difference vs placebo (95\% Cl) & & $0.8(0.8,0.9)$ & $0.8(0.7,0.9)$ \\
\hline p-value & & 0.002 & $<0.001$ \\
\hline Relative change from baseline at day 28 & $1.0(0.9,1.0)$ & $0.8(0.8,0.9)$ & $0.8(0.7,0.9)$ \\
\hline Difference vs placebo (95\% Cl) & & $0.9(0.8,1.0)$ & $0.8(0.7,0.9)$ \\
\hline$p$-value & & 0.011 & 0.001 \\
\hline
\end{tabular}

Log-transformed data. Baseline data are gMean (\% gCV), change from baseline data are adjusted gMean ratio (95\% Cl) based on analysis of covariance (ANCOVA) in the full analysis set. ${ }^{*} 63.8(65.5)$ for day 1 analysis $(n=21) .{ }^{\dagger} 72.8(55.5)$ for day 1 analysis $(n=21)$.

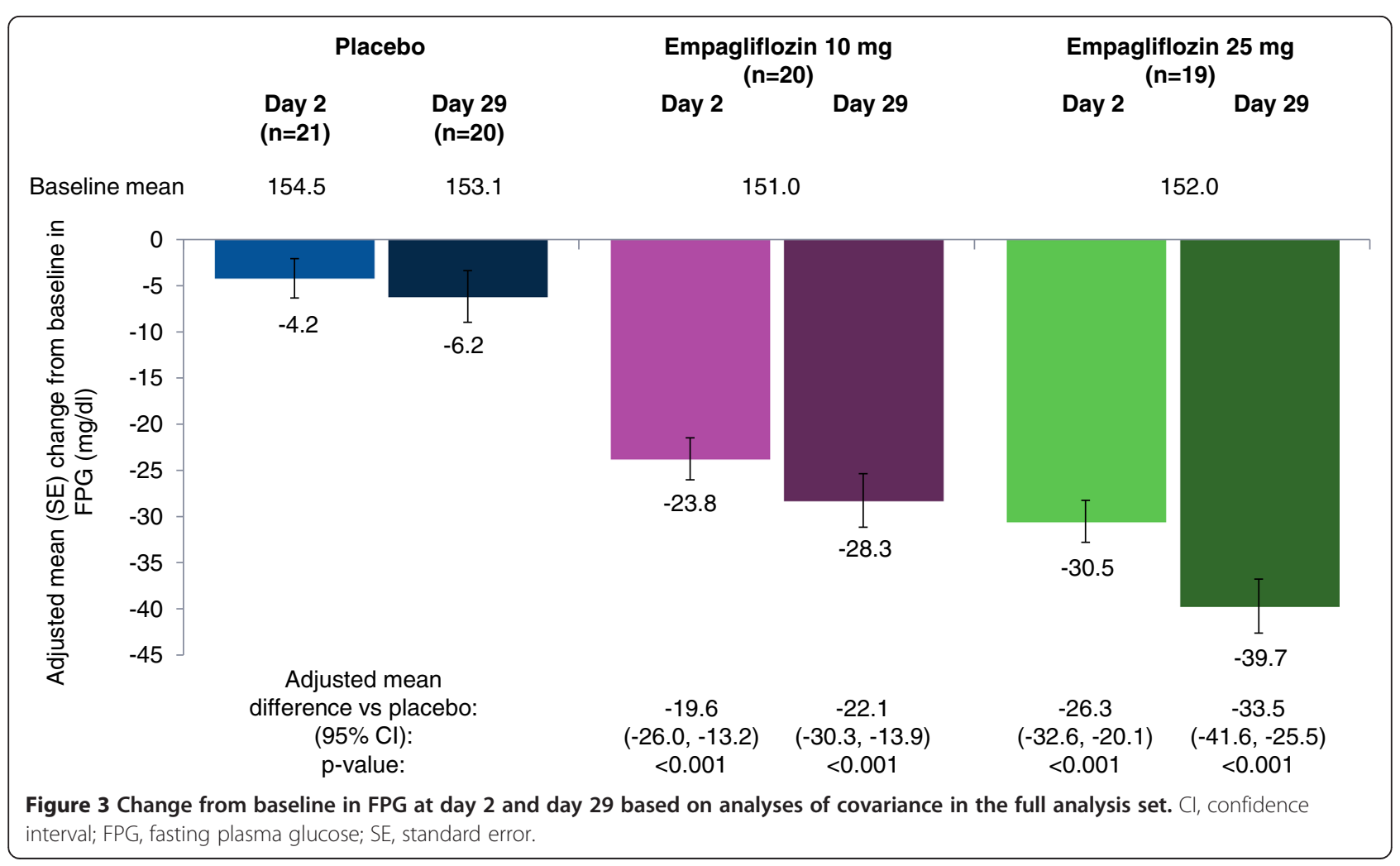




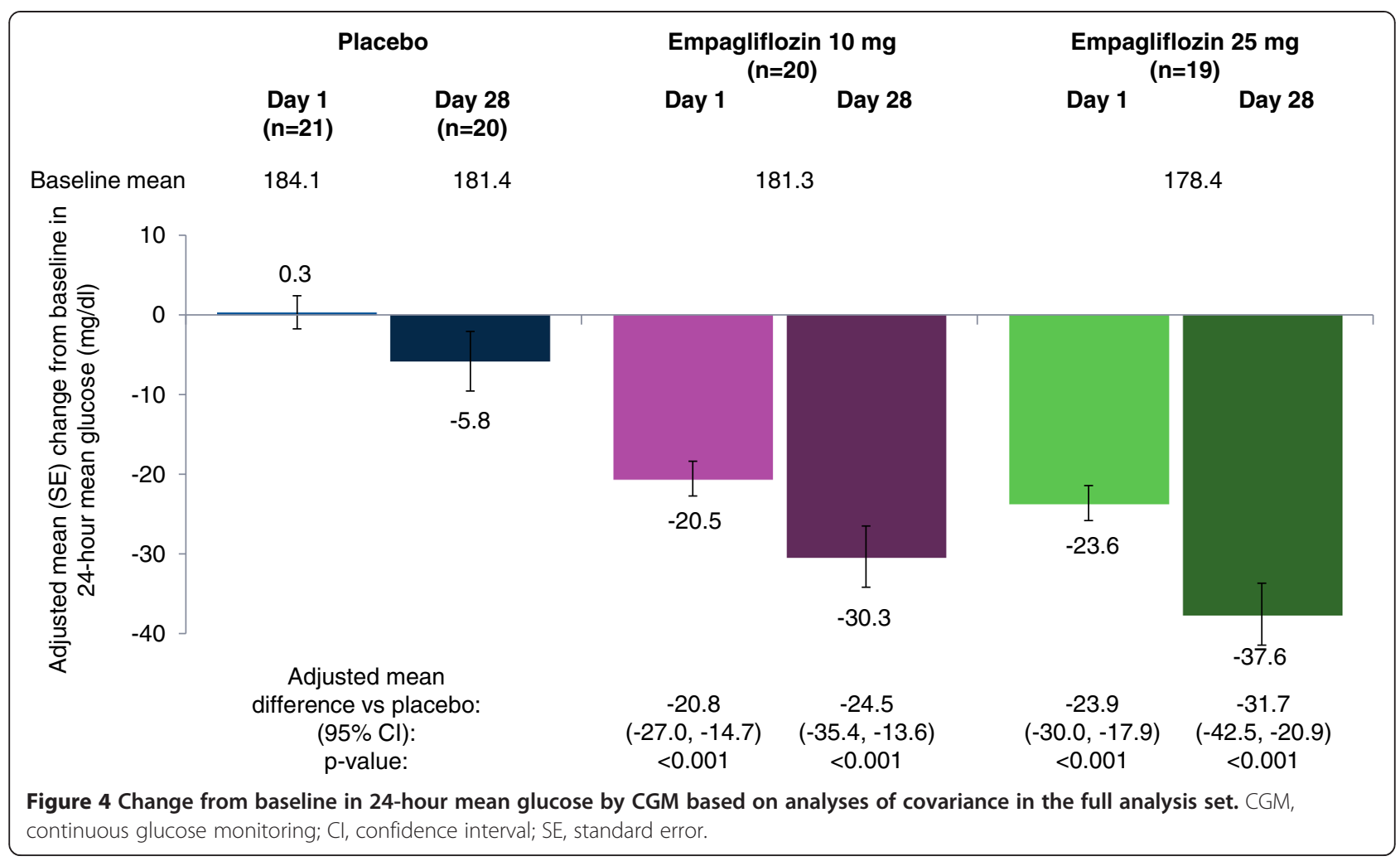

seemed to be slightly greater with empagliflozin $25 \mathrm{mg}$ than empagliflozin $10 \mathrm{mg}$ (Figure 5). At day 1, adjusted mean (SE) changes from baseline in MAGE were 15.1 (3.5), 11.0 (3.7) and 8.9 (3.7) $\mathrm{mg} / \mathrm{dl}$ with placebo, empagliflozin $10 \mathrm{mg}$ and empagliflozin $25 \mathrm{mg}$, respectively. At day 28, adjusted mean (SE) changes from baseline in MAGE were -4.7 (4.5), -3.7 (4.6) and -2.2 (4.7) $\mathrm{mg} / \mathrm{dl}$ with placebo, empagliflozin $10 \mathrm{mg}$ and empagliflozin $25 \mathrm{mg}$, respectively. Differences were not statistically significant with either empagliflozin dose compared with placebo at either timepoint. Compared with placebo, empagliflozin $10 \mathrm{mg}$ and $25 \mathrm{mg}$ reduced the percentage of time with glucose $\geq 180 \mathrm{mg} / \mathrm{dl} \quad(\mathrm{p}<0.01)$, and increased the percentage of time with normoglycemia (glucose $\geq 70$ to $<180 \mathrm{mg} / \mathrm{dl}$ ) $(\mathrm{p}<0.01)$ without significantly increasing the percentage of time with hypoglycemia (glucose $<70 \mathrm{mg} / \mathrm{dl}$ ) (Figure 6; Additional file 1: Table S2).

At day 29, adjusted mean (SE) changes from baseline in HbA1c were $-0.11(0.06) \%$ with placebo compared with $-0.46(0.06) \%$ with empagliflozin $10 \mathrm{mg}$ (adjusted mean $[95 \% \mathrm{CI}]$ difference: $-0.35 \%[-0.52,-0.19]$; $\mathrm{p}<0.001)$ and $-0.63(0.06) \%$ with empagliflozin $25 \mathrm{mg}$ (adjusted mean [95\% CI] difference: $-0.52 \%[-0.68,-0.35] ; \mathrm{p}<0.001)$.

Consistent with reductions in PPG, the excretion of 8iso-PGF2 $\alpha$, a marker of oxidative stress, was significantly reduced from baseline with empagliflozin $10 \mathrm{mg}$ and $25 \mathrm{mg}$ compared with placebo at day 28 in the fasting state (Table 3). Reductions from baseline in the excretion of 8 -iso-PGF2 $\alpha$ in the 24 hours after study drug administration were only significantly different with empagliflozin $25 \mathrm{mg}$ compared with placebo at day 28 (Table 3 ).

\section{Safety}

AEs were reported in 2 patients (9.5\%) on placebo, 3 patients (15.0\%) on empagliflozin $10 \mathrm{mg}$ and 3 patients (15.8\%) on empagliflozin $25 \mathrm{mg}$. No severe AEs, serious AEs, or AEs leading to discontinuation occurred. No hypoglycemic AEs were reported. One patient (on empagliflozin $25 \mathrm{mg}$ ) experienced an AE consistent with genital infection (bartholinitis). No AEs consistent with UTI or volume depletion were reported. No AEs of diabetic ketoacidosis or those related to abnormal ketone body levels were reported.

At day 29, weight was reduced from baseline by $0.9 \mathrm{~kg}$, $1.7 \mathrm{~kg}$ and $2.1 \mathrm{~kg}$ with placebo, empagliflozin $10 \mathrm{mg}$ and $25 \mathrm{mg}$, respectively (Additional file 1: Table S3). Acute changes in SBP and diastolic BP (DBP) (at day 2) with empagliflozin compared with placebo were small, and more pronounced reductions were observed at day 29 (Additional file 1: Table S3). In contrast, pulse rate appeared to increase with empagliflozin compared with placebo at day 2 , but changes from baseline in pulse rate were similar between empagliflozin and placebo at day 29 (Additional file 1: Table S3).

Compared with placebo, there were no significant differences in changes from baseline in total cholesterol or 


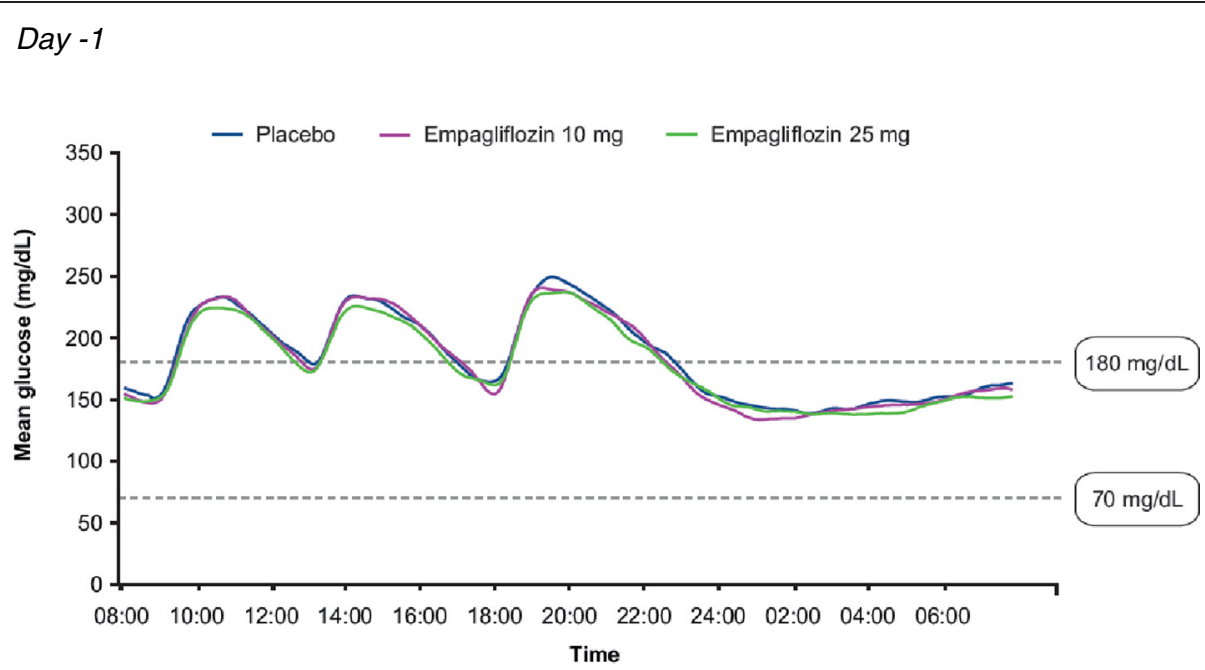

Day 1

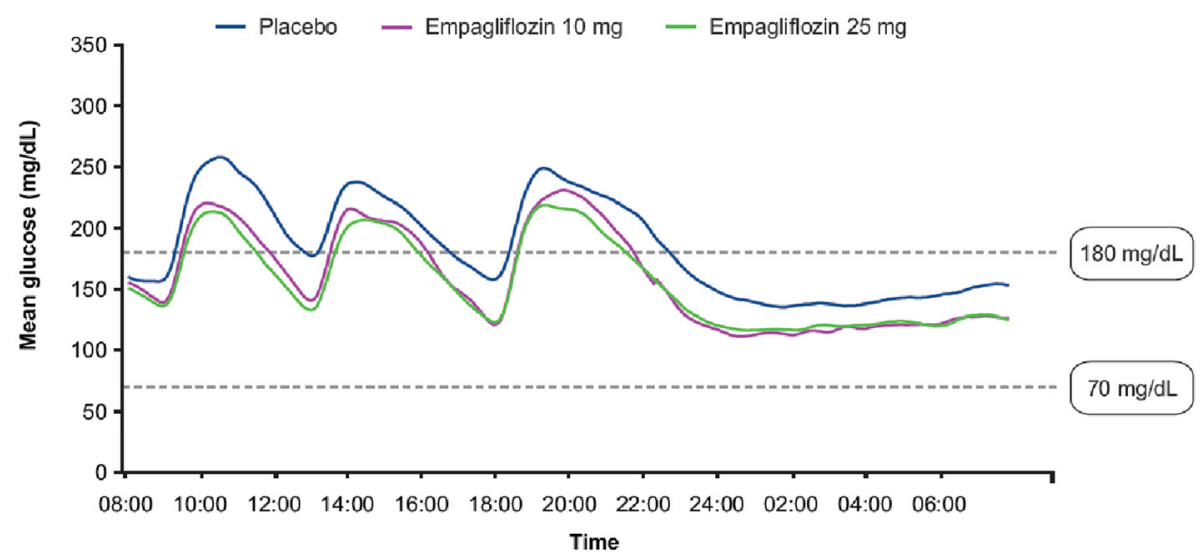

Day 28

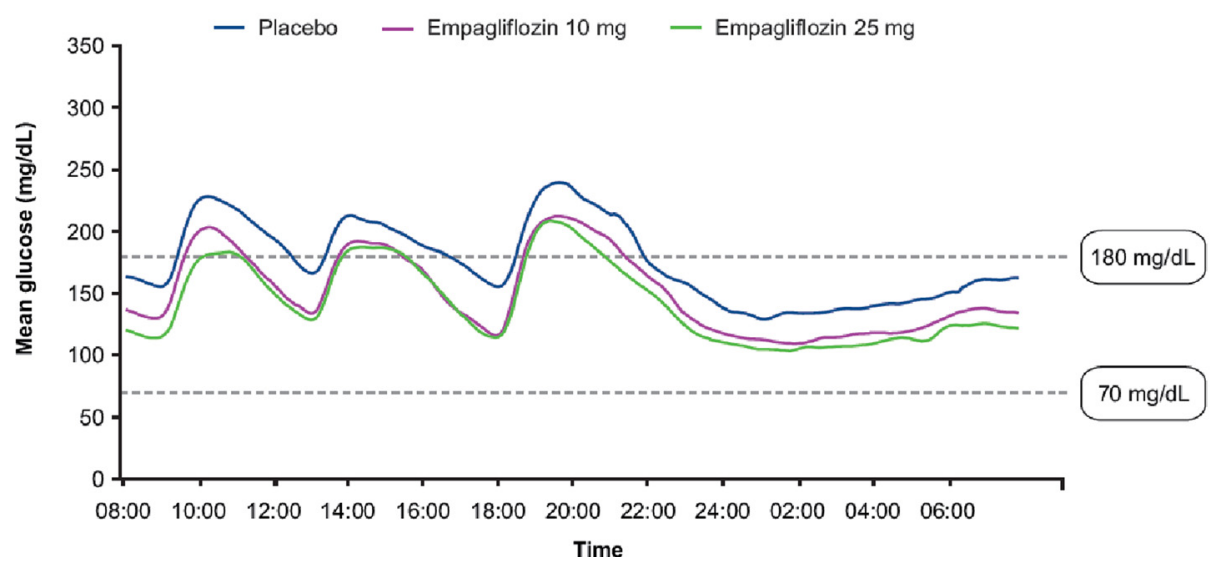

Figure 5 Mean glucose over 24 hours by CGM. CGM, continuous glucose monitoring. 


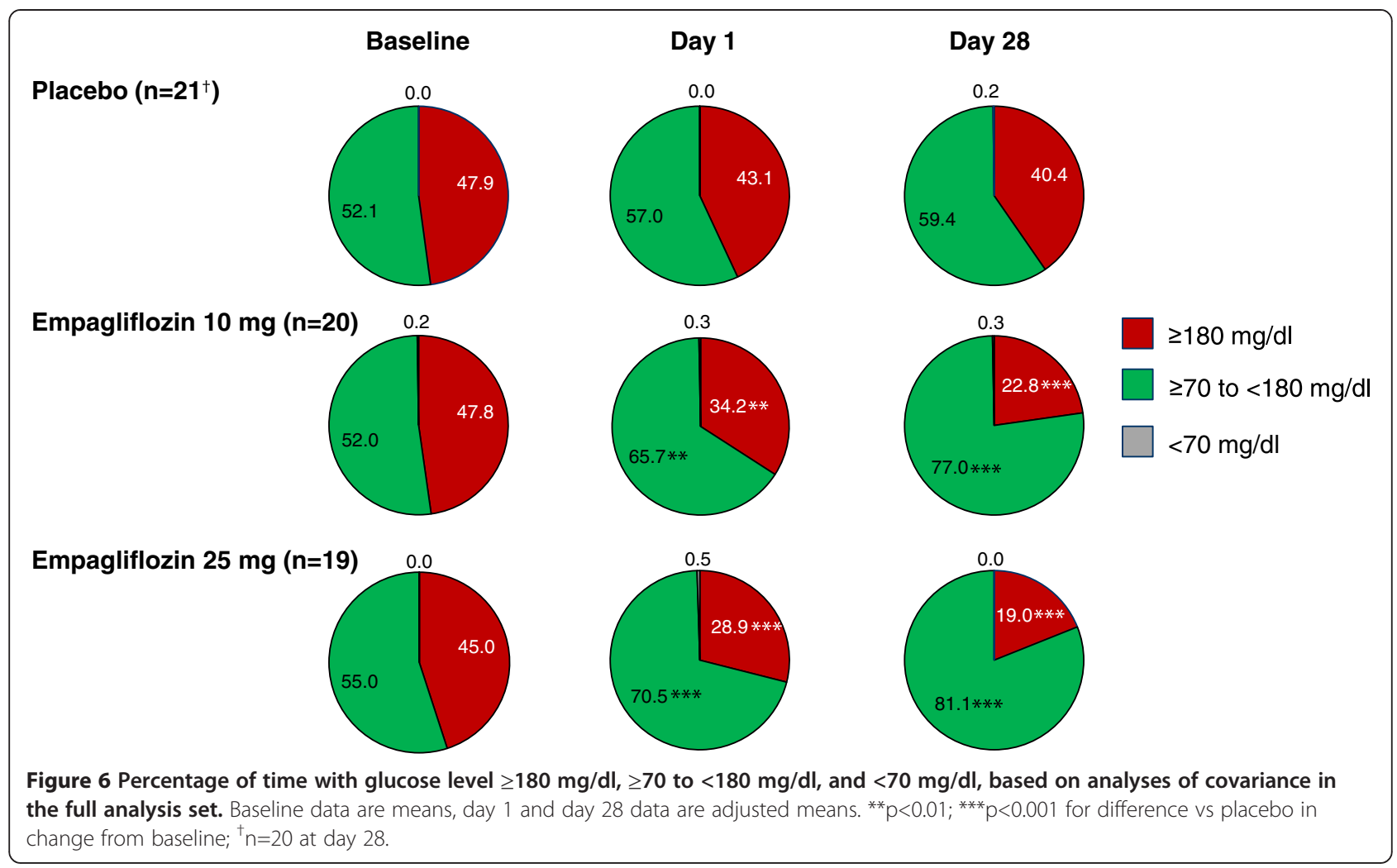

LDL-cholesterol with empagliflozin $10 \mathrm{mg}$ or $25 \mathrm{mg}$ (Table 4). Compared with placebo, HDL-cholesterol was significantly increased with empagliflozin $10 \mathrm{mg}$ and $25 \mathrm{mg}$, and triglycerides were significantly reduced with empagliflozin $10 \mathrm{mg}$ and $25 \mathrm{mg}$, at day 29. There were significant increases from baseline in free fatty acids with empagliflozin $25 \mathrm{mg}$, but not with empagliflozin $10 \mathrm{mg}$, compared with placebo at day 29. There were significant increases from baseline in blood ketone bodies with empagliflozin $10 \mathrm{mg}$ and $25 \mathrm{mg}$ compared with placebo at day 29 (Table 4).
No clinically relevant changes in electrolytes (sodium, potassium, calcium, magnesium, phosphate) were observed in any group at the end of treatment (Additional file 1: Table S4). Changes from baseline in hematocrit and eGFR were generally small in all groups (Additional file 1: Table S4).

\section{Conclusions}

This study was conducted to evaluate the effect of empagliflozin as monotherapy for 28 days on PPG and 24-hour

Table 3 Changes in urinary excretion of 8-iso-PGF2a at day 28

\begin{tabular}{|c|c|c|c|}
\hline & Placebo $(n=20)$ & Empagliflozin 10 mg $(n=20)$ & Empagliflozin $25 \mathrm{mg}(\mathrm{n}=19)$ \\
\hline \multicolumn{4}{|l|}{ Fasting state, $\mathrm{pg} / \mathrm{ml}$} \\
\hline Baseline & $197.8(27.0)$ & $194.6(29.4)$ & $146.5(18.5)$ \\
\hline Change from baseline at day 28 & $40.6(22.6)$ & $-48.1(23.3)$ & $-33.5(23.7)$ \\
\hline Difference vs placebo (95\% Cl) & & $-88.6(-154.6,-22.7)$ & $-74.0(-139.8,-8.2)$ \\
\hline p-value & & 0.010 & 0.028 \\
\hline \multicolumn{4}{|c|}{ In 24 hours after drug administration, $\mathrm{pg} / \mathrm{ml}$} \\
\hline Baseline & $115.5(11.0)$ & $138.3(20.6)$ & $148.6(21.7)$ \\
\hline Change from baseline at day 28 & $-3.7(10.3)$ & $-28.4(10.4)$ & $-46.8(10.6)$ \\
\hline Difference vs placebo (95\% Cl) & & $-24.7(-54.5,5.2)$ & $-43.1(-72.9,-13.3)$ \\
\hline p-value & & 0.103 & 0.006 \\
\hline
\end{tabular}


Table 4 Changes in fasting serum lipids and ketone bodies at day 29

\begin{tabular}{|c|c|c|c|}
\hline & Placebo $(n=20)$ & Empagliflozin $10 \mathrm{mg}(\mathrm{n}=20)$ & Empagliflozin $25 \mathrm{mg}(\mathrm{n}=19)$ \\
\hline \multicolumn{4}{|l|}{ Total cholesterol, mg/dl } \\
\hline Baseline & $212.8(7.7)$ & $200.1(8.4)$ & $208.7(9.1)$ \\
\hline Change from baseline at day 29 & $-0.8(3.6)$ & $3.2(3.7)$ & $1.1(3.7)$ \\
\hline Difference vs placebo (95\% Cl) & & $4.0(-6.6,14.6)$ & $1.9(-8.6,12.3)$ \\
\hline p-value & & 0.455 & 0.722 \\
\hline \multicolumn{4}{|l|}{ HDL-cholesterol, mg/dl } \\
\hline Baseline & $46.8(2.2)$ & $47.6(2.8)$ & $46.8(2.8)$ \\
\hline Change from baseline at day 29 & $0.1(1.2)$ & $4.7(1.3)$ & $7.4(1.3)$ \\
\hline Difference vs placebo (95\% Cl) & & $4.5(1.0,8.1)$ & $7.2(3.7,10.8)$ \\
\hline$p$-value & & 0.014 & $<0.001$ \\
\hline \multicolumn{4}{|l|}{ LDL-cholesterol, mg/dl } \\
\hline Baseline & $128.7(6.3)$ & $124.9(8.4)$ & $130.5(8.5)$ \\
\hline Change from baseline at day 29 & $-1.3(3.2)$ & $3.4(3.3)$ & $4.3(3.3)$ \\
\hline Difference vs placebo (95\% Cl) & & $4.7(-4.6,14.0)$ & $5.7(-3.5,14.8)$ \\
\hline $\mathrm{p}$-value & & 0.314 & 0.221 \\
\hline \multicolumn{4}{|l|}{ Triglycerides, mg/dl* } \\
\hline Baseline & $159.6(51.0)$ & $131.5(34.9)$ & $142.2(48.0)$ \\
\hline Relative change from baseline at day 29 & $1.0(0.9,1.1)$ & $0.8(0.7,0.9)$ & $0.7(0.6,0.8)$ \\
\hline Difference vs placebo (95\% Cl) & & $0.8(0.7,1.0)$ & $0.7(0.6,0.8)$ \\
\hline$p$-value & & 0.037 & $<0.001$ \\
\hline \multicolumn{4}{|l|}{ Free fatty acids, mg/dl } \\
\hline Baseline & $10.8(0.8)$ & $9.6(0.7)$ & $9.3(0.6)$ \\
\hline Change from baseline at day 29 & $3.1(0.8)$ & $4.8(0.8)$ & $7.4(0.8)$ \\
\hline Difference vs placebo (95\% Cl) & & $1.7(-0.6,4.1)$ & $4.3(2.0,6.7)$ \\
\hline$p$-value & & 0.149 & $<0.001$ \\
\hline \multicolumn{4}{|l|}{ Ketone bodies, $\mu \mathrm{mol} / \mathrm{l}$} \\
\hline Baseline & $86.8(10.2)$ & $78.1(12.0)$ & $69.4(10.8)$ \\
\hline Change from baseline at day 29 & $-12.2(44.0)$ & $139.5(44.7)$ & $408.0(45.5)$ \\
\hline Difference vs placebo $(95 \% \mathrm{Cl})$ & & $151.7(24.4,279.0)$ & $420.2(293.3,547.2)$ \\
\hline $\mathrm{p}$-value & & 0.021 & $<0.001$ \\
\hline
\end{tabular}

Unless otherwise indicated, baseline data are mean (standard error [SE]), change from baseline data are adjusted mean (SE) based on analysis of covariance (ANCOVA) in the treated set. Fasting measurements. *Log-transformed data; baseline data are gMean (\%CV) and change from baseline data are adjusted gMean ratio $(95 \% \mathrm{Cl})$.

glycemic variability in Japanese patients with T2DM. Significant reductions from baseline in $\mathrm{AUC}_{1-4 \mathrm{~h}}$ for PPG were observed after acute and subchronic treatment with empagliflozin, with $80-90 \%$ of the reduction in $\mathrm{AUC}_{1-4 \mathrm{~h}}$ for PPG already achieved at day 1 .

At day 28, although the reductions from baseline in AUC for PPG with empagliflozin observed after dinner were of a lower magnitude than those observed after breakfast, the reductions observed after dinner were significant. These observations were consistent with reductions in 2-hour PPG. The sustained effect of empagliflozin on PPG from morning to evening support once-daily administration of empagliflozin.
Of note, the reduction in PPG in this study was accompanied by a reduction in postprandial insulin levels. In contrast to insulin secretagogues and incretins, empagliflozin's mode of action is independent of beta-cell function and insulin secretion [18]. By increasing urinary glucose excretion, empagliflozin reduces plasma glucose levels leading to a reduction in plasma insulin levels [29].

CGM can provide valuable information on the magnitude and duration of glucose fluctuations [30]. In this study, empagliflozin improved daily blood glucose control measured using CGM, with the curves of mean 24-hour glucose lower at day 1 and day 28 than at baseline. Consistent with changes in FPG, PPG and HbAlc, slightly greater 
reductions in 24-hour mean glucose and mean glucose levels over 24 hours were observed with empagliflozin $25 \mathrm{mg}$ compared with empagliflozin $10 \mathrm{mg}$ at day 28 . Empagliflozin had a significant effect on FPG as well as PPG, and the reductions in PPG were not substantially different to the reductions in FPG. Therefore, the curves of mean 24-hour glucose with empagliflozin showed a parallel shift downward and MAGE was not significantly reduced by empagliflozin. Variable responses in FPG and PPG have been observed with empagliflozin in other clinical trials in patients with T2DM [21,22]. Further CGM data with SGLT2 inhibitors in patients with T2DM are needed to illuminate the effect of this class of drugs on MAGE.

Tight glucose control is important to reduce the risk of micro- and macrovascular complications [9], and to avoid the adverse effects on morbidity, mortality and quality of life associated with hypoglycemia [31]. Importantly, CGM measurements in this study showed that empagliflozin increased the time patients spent with normoglycemia without increasing the time spent at a hypoglycemic level.

Treatment with empagliflozin is consistently associated with weight loss in patients with T2DM [21-26]. This reflects loss of both trunk fat and limb fat, and reductions in both abdominal visceral and subcutaneous adipose tissue [32]. After 2 years' treatment with empagliflozin $25 \mathrm{mg}$ as add-on to metformin, approximately $90 \%$ of the weight loss observed was due to fat loss [32]. Empagliflozininduced urinary glucose excretion results in calorie loss and reduced plasma glucose levels with an increased glucagon-to-insulin ratio [29], leading to lipolysis, increased free fatty acid levels and ketogenesis. The most common causes of ketosis are physiological conditions, in which mild to moderate elevations of circulating ketone bodies occur in response to fasting or prolonged exercise, with ketone body levels not uncommonly rising to the range of $1 \pm 2 \mathrm{mM}[33,34]$. In this study, the average increase in ketone bodies was modest, with adjusted mean levels of 218, 486 and $66 \mu \mathrm{mol} / \mathrm{l}$ for empagliflozin $10 \mathrm{mg}$, empagliflozin $25 \mathrm{mg}$ and placebo, respectively, at day 29 . The highest level of ketone bodies observed in our study in an individual patient was $1449 \mu \mathrm{mol} / \mathrm{l}$, which is comparable with levels of up to about $1300 \mu \mathrm{mol} / \mathrm{l}$ reported for subjects without diabetes after an overnight fast [35]. Diabetic ketoacidosis is typically accompanied by levels of ketone bodies $>3000 \mu \mathrm{mol} / \mathrm{l}[33]$ and develops almost exclusively in states of absolute insulin deficiency. In contrast, the lowering of insulin levels with empagliflozin is probably secondary to the reduction in plasma glucose levels via increased urinary glucose excretion, which is accompanied by an improvement in beta-cell function [29]. Therefore, the empagliflozin-induced increase in ketone bodies most likely reflects an adaptive change, with ketone levels in the range of physiological conditions, which is unlikely to put patients at risk of ketoacidosis in the absence of absolute (endogenous or exogenous) insulin deficiency or extreme (ketogenic) diets.

Patients with T2DM have an increased risk of developing cardiovascular events compared with the general population [36], which is related to the prevalence of the classical cardiovascular risk factors of hypertension and dyslipidemia, in addition to other important factors such as glycemic control, oxidative stress, and obesity [37]. Elevated PPG is an independent risk factor for cardiovascular disease [10,11]; however, improvements in PPG have not been shown to translate into reduced risk of cardiovascular disease [38]. Empagliflozin improves glycemic control with a low risk of hypoglycemia, leads to weight loss and reduces blood pressure, possibly due to diuretic effects, weight loss, or direct vascular effects [21-26,39,40]; further, as demonstrated in this study, empagliflozin reduces PPG and 8-iso-PGF2 $\alpha$, a marker of oxidative stress that is an independent risk marker for cardiovascular disease [41]. A cardiovascular outcome trial (EMPA-REG OUTCOME ${ }^{\mathrm{mw}}$; NCT01131676) is investigating the effect of empagliflozin in patients with T2DM and high cardiovascular risk [42].

In conclusion, empagliflozin $10 \mathrm{mg}$ or $25 \mathrm{mg}$ as monotherapy for 28 days significantly reduced PPG and FPG and improved daily blood glucose control in Japanese patients with T2DM, without increasing time spent with a hypoglycemic blood glucose level.

\section{Additional file}

Additional file 1: Table S1. Test meals. Table S2. Changes in

percentage of time with glucose level $\geq 180 \mathrm{mg} / \mathrm{dl}$, $\geq 70$ to $<180 \mathrm{mg} / \mathrm{dl}$, and $<70 \mathrm{mg} / \mathrm{dl}$. Table S3. Changes in blood pressure, pulse rate and weight. Table S4. Laboratory measurements.

\section{Abbreviations}

AE: Adverse event; ANCOVA: Analysis of covariance; AUC: Area under the glucose concentration-time curve; BMI: Body mass index; CGM: Continuous glucose monitoring; Cl: Confidence interval; DBP: Diastolic blood pressure; eGFR: Estimated glomerular filtration rate; FAS: Full analysis set; FPG: Fasting plasma glucose; HbA1c: Glycated hemoglobin; HDL-cholesterol: High-density lipoprotein cholesterol; LDL-cholesterol: Low-density lipoprotein cholesterol; MAGE: Mean amplitude of glucose excursions; MedDRA: Medical Dictionary for Drug Regulatory Activities; MTT: Meal tolerance test; PPG: Postprandial glucose; SBP: Systolic blood pressure; SD: Standard deviation; SE: Standard error; SGLT2: Sodium glucose cotransporter 2; T2DM: Type 2 diabetes mellitus; UTI: Urinary tract infection.

\section{Competing interests}

RN has received research support from Japan Diabetes Foundation, Boehringer Ingelheim, Daiichi-Sankyo and Astellas, has participated in speaker's bureau/advisory panels for Novo Nordisk, Eli Lilly, Sanofi, Kissei, Astellas, Boehringer Ingelheim, Daiichi-Sankyo, Tanabe-Mitsubishi, Astra Zeneca, Kowa, Ono, Johnson \& Johnson, Medtronic, Takeda and Astellas, and served as a consultant for Boehringer Ingelheim and Eli Lilly. KK, YT, TH, AS, SSL and UCB are employees of Boehringer Ingelheim. SSL owns shares in Novo Nordisk A/S and shares in dynamically traded investment funds which may own stocks from drug companies. KI works on behalf of Boehringer Ingelheim. 


\section{Authors' contributions}

$\mathrm{RN}$ contributed to the study design, acquisition and interpretation of data and reviewed/edited the manuscript. KK, YT, KI, TH, AS, SSL and UCB contributed to the study design and interpretation of data and reviewed/ edited the manuscript. All authors read and approved the final manuscript.

\section{Acknowledgements}

This study was funded by Boehringer Ingelheim and Eli Lilly and Company. Medical writing assistance, supported financially by Boehringer Ingelheim, was provided by Elizabeth $\mathrm{Ng}$ and Wendy Morris of Fleishman-Hillard Group, Ltd during the preparation of this manuscript. The authors were fully responsible for all content and editorial decisions, were involved at all stages of manuscript development and have approved the final version. The authors thank Nima Soleymanlou, Boehringer Ingelheim, for his advice on interpretation of the CGM data.

\section{Author details}

${ }^{1}$ Jikei University School of Medicine, Tokyo, Japan. ${ }^{2}$ Nippon Boehringer Ingelheim Co. Ltd, Osaki 2-1-1, ThinkPark Tower, Tokyo 141-6017, Japan. ${ }^{3}$ EPS Corporation, Tokyo, Japan. ${ }^{4}$ Boehringer Ingelheim Pharma GmbH \& Co. KG, Ingelheim, Germany. ${ }^{5}$ Boehringer Ingelheim Pharmaceuticals, Inc, Ridgefield, CT, USA

Received: 13 November 2014 Accepted: 28 December 2014 Published online: 30 January 2015

\section{References}

1. Guariguata L, Whiting DR, Hambleton I, Beagley J, Linnenkamp U, Shaw JE. Global estimates of diabetes prevalence for 2013 and projections for 2035. Diabetes Res Clin Pract. 2014;103(2):137-49.

2. Oba S, Nagata C, Nakamura K, Takatsuka N, Shimizu H. Self-reported diabetes mellitus and risk of mortality from all causes, cardiovascular disease, and cancer in Takayama: a population-based prospective cohort study in Japan. J Epidemiol. 2008;18(5):197-203.

3. Bonora E, Corrao G, Bagnardi V, Ceriello A, Comaschi M, Montanari P, et al. Prevalence and correlates of post-prandial hyperglycaemia in a large sample of patients with type 2 diabetes mellitus. Diabetologia. 2006;49(5):846-54.

4. Bonora E, Calcaterra F, Lombardi S, Bonfante N, Formentini G, Bonadonna $\mathrm{RC}$, et al. Plasma glucose levels throughout the day and $\mathrm{HbA}(1 \mathrm{c})$ interrelationships in type 2 diabetes: implications for treatment and monitoring of metabolic control. Diabetes Care. 2001;24(12):2023-9.

5. Woerle HJ, Neumann C, Zschau S, Tenner S, Irsigler A, Schirra J, et al. Impact of fasting and postprandial glycemia on overall glycemic control in type 2 diabetes: importance of postprandial glycemia to achieve target $\mathrm{HbA1c}$ levels. Diabetes Res Clin Pract. 2007;77(2):280-5.

6. Peter R, Dunseath G, Luzio SD, Owens DR. Estimates of the relative and absolute diurnal contributions of fasting and post-prandial plasma glucose over a range of hyperglycaemia in type 2 diabetes. Diabetes Metab. 2013:39(4):337-42.

7. Handelsman Y, Mechanick Jl, Blonde L, Grunberger G, Bloomgarden ZT, Bray GA, et al. American association of clinical endocrinologists medical guidelines for clinical practice for developing a diabetes mellitus comprehensive care plan. Endocr Pract. 2011;17 Suppl 2:1-53.

8. International Diabetes Federation: Guideline for management of postmeal glucose in diabetes [https://www.idf.org/2011-guideline-managementpostmeal-glucose-diabetes]

9. Inzucchi SE, Bergenstal RM, Buse JB, Diamant M, Ferrannini E, Nauck M, et al. Management of hyperglycemia in type 2 diabetes: a patient-centered approach. Position statement of the American Diabetes Association (ADA) and the European Association for the Study of Diabetes (EASD). Diabetes Care. 2012;35(6):1364-79.

10. Cavalot F, Petrelli A, Traversa M, Bonomo K, Fiora E, Conti M, et al. Postprandial blood glucose is a stronger predictor of cardiovascular events than fasting blood glucose in type 2 diabetes mellitus, particularly in women: lessons from the San Luigi Gonzaga diabetes study. J Clin Endocrinol Metab. 2006;91(3):813-9.

11. Cavalot F, Pagliarino A, Valle M, Di ML, Bonomo K, Massucco P, et al. Postprandial blood glucose predicts cardiovascular events and all-cause mortality in type 2 diabetes in a 14-year follow-up: lessons from the San Luigi Gonzaga diabetes study. Diabetes Care. 2011;34(10):2237-43.
12. Ceriello A, Esposito K, Piconi L, Ihnat MA, Thorpe JE, Testa R, et al. Oscillating glucose is more deleterious to endothelial function and oxidative stress than mean glucose in normal and type 2 diabetic patients. Diabetes. 2008:57(5):1349-54.

13. Kawano H, Motoyama T, Hirashima O, Hirai N, Miyao Y, Sakamoto T, et al. Hyperglycemia rapidly suppresses flow-mediated endothelium-dependent vasodilation of brachial artery. J Am Coll Cardiol. 1999;34(1):146-54.

14. Sartore G, Chilelli NC, Burlina S, Lapolla A. Association between glucose variability as assessed by continuous glucose monitoring (CGM) and diabetic retinopathy in type 1 and type 2 diabetes. Acta Diabetol. 2013;50(3):437-42

15. Su G, Mi S, Tao H, Li Z, Yang H, Zheng $H$, et al. Association of glycemic variability and the presence and severity of coronary artery disease in patients with type 2 diabetes. Cardiovasc Diabetol. 2011;10:19.

16. Bonds DE, Miller ME, Bergenstal RM, Buse JB, Byington RP, Cutler JA, et al. The association between symptomatic, severe hypoglycaemia and mortality in type 2 diabetes: retrospective epidemiological analysis of the ACCORD study. BMJ. 2010;340:b4909.

17. Hsu PF, Sung SH, Cheng HM, Yeh JS, Liu WL, Chan WL, et al. Association of clinical symptomatic hypoglycemia with cardiovascular events and total mortality in type 2 diabetes: a nationwide population-based study. Diabetes Care. 2013;36(4):894-900.

18. DeFronzo RA, Davidson JA, del Prato S. The role of the kidneys in glucose homeostasis: a new path towards normalizing glycaemia. Diabetes Obes Metab. 2012;14(1):5-14

19. Kanada S, Koiwai K, Taniguchi A, Sarashina A, Seman L, Woerle HJ. Pharmacokinetics, pharmacodynamics, safety and tolerability of 4 weeks' treatment with empagliflozin in Japanese patients with type 2 diabetes mellitus. J Diabetes Investig. 2013;4(6):613-7.

20. Grempler R, Thomas L, Eckhardt M, Himmelsbach F, Sauer A, Sharp DE, et al. Empagliflozin, a novel selective sodium glucose cotransporter-2 (SGLT-2) inhibitor: characterisation and comparison with other SGLT-2 inhibitors. Diabetes Obes Metab. 2012;14(1):83-90.

21. Häring $H-U$, Merker $L$, Seewaldt-Becker E, Weimer M, Meinicke T, Woerle HJ, et al. Empagliflozin as add-on to metformin plus sulfonylurea in patients with type 2 diabetes: a 24-week randomized, double-blind, placebocontrolled trial. Diabetes Care. 2013;36(11):3396-404.

22. Häring $\mathrm{H}-\mathrm{U}$, Merker $\mathrm{L}$, Seewaldt-Becker $\mathrm{E}$, Weimer M, Meinicke T, Broedl UC et al. Empagliflozin as add-on to metformin in patients with type 2 diabetes: a 24-week, randomized, double-blind, placebo-controlled trial. Diabetes Care. 2014;37(6):1650-9.

23. Kovacs CS, Seshiah V, Swallow $R$, Jones $R$, Rattunde $H$, Woerle $H J$, et al. Empagliflozin improves glycaemic and weight control as add-on therapy to pioglitazone or pioglitazone plus metformin in patients with type 2 diabetes: a 24-week, randomized, placebo-controlled trial. Diabetes Obes Metab. 2014;16(2):147-58.

24. Roden M, Weng J, Eilbracht J, Delafont B, Kim G, Woerle HJ, et al. Empagliflozin monotherapy with sitagliptin as an active comparator in patients with type 2 diabetes: a randomised, double-blind, placebocontrolled, phase 3 trial. Lancet Diabetes Endocrinol. 2013;1(3):208-19.

25. Kadowaki T, Haneda M, Inagaki N, Terauchi Y, Taniguchi A, Koiwai K, et al. Empagliflozin monotherapy in Japanese patients with type 2 diabetes mellitus: a randomized, 12-week, double-blind, placebo-controlled, phase II trial. Adv Ther. 2014;31(6):621-38

26. Woerle HJ, Kadowaki T, Haneda M, Inagaki A, Sakamoto M, Koiwai K, et al. Safety and efficacy of empagliflozin monotherapy in a 52-week study in Japanese patients with type 2 diabetes mellitus. Diabetologia. 2013;56 Suppl 1:S371-2.

27. Matsuo S, Imai E, Horio M, Yasuda Y, Tomita K, Nitta K, et al. Revised equations for estimated GFR from serum creatinine in Japan. Am J Kidney Dis. 2009;53(6):982-92

28. Service FJ, Molnar GD, Rosevear JW, Ackerman E, Gatewood LC, Taylor WF. Mean amplitude of glycemic excursions, a measure of diabetic instability. Diabetes. 1970;19(9):644-55.

29. Ferrannini E, Muscelli E, Frascerra S, Baldi S, Mari A, Heise T, et al. Metabolic response to sodium-glucose cotransporter 2 inhibition in type 2 diabetic patients. J Clin Invest. 2014;124(2):499-508.

30. Klonoff DC. Continuous glucose monitoring: roadmap for 21 st century diabetes therapy. Diabetes Care. 2005;28(5):1231-9.

31. Barnett AH, Cradock S, Fisher M, Hall G, Hughes E, Middleton A. Key considerations around the risks and consequences of hypoglycaemia in people with type 2 diabetes. Int J Clin Pract. 2010;64(8):1121-9. 
32. Ridderstrale M, Andersen KR, Zeller C, Kim G, Woerle HJ, Broedl UC. Comparison of empagliflozin and glimepiride as add-on to metformin in patients with type 2 diabetes: a 104-week randomised, active-controlled, double-blind, phase 3 trial. Lancet Diabetes Endocrinol. 2014;2(9):691-700.

33. Laffel L. Ketone bodies: a review of physiology, pathophysiology and application of monitoring to diabetes. Diabetes Metab Res Rev. 1999;15(6):412-26

34. Koeslag JH, Noakes TD, Sloan AW. Post-exercise ketosis. J Physiol. 1980;301:79-90.

35. Foster K, Alberti KG, Hinks L, Lloyd B, Postle A, Smythe P, et al. Blood intermediary metabolite and insulin concentrations after an overnight fast: reference ranges for adults, and interrelations. Clin Chem. 1978;24(9):1568-72.

36. Fox CS, Pencina MJ, Wilson PW, Paynter NP, Vasan RS, D'Agostino Sr RB. Lifetime risk of cardiovascular disease among individuals with and without diabetes stratified by obesity status in the Framingham heart study. Diabetes Care. 2008;31(8):1582-4.

37. Martin-Timon I, Sevillano-Collantes C, Segura-Galindo A, Del Canizo-Gomez FJ. Type 2 diabetes and cardiovascular disease: have all risk factors the same strength? World J Diabetes. 2014:5(4):444-70.

38. Raz I, Wilson PW, Strojek K, Kowalska I, Bozikov V, Gitt AK, et al. Effects of prandial versus fasting glycemia on cardiovascular outcomes in type 2 diabetes: the HEART2D trial. Diabetes Care. 2009;32(3):381-6.

39. Baker WL, Smyth LR, Riche DM, Bourret EM, Chamberlin KW, White WB. Effects of sodium-glucose co-transporter 2 inhibitors on blood pressure: a systematic review and meta-analysis. J Am Soc Hypertens. 2014;8(4):262-75.

40. Tikkanen I, Narko K, Zeller C, Green A, Salsali A, Broedl UC, Woerle H: Empagliflozin reduces blood pressure in patients with type 2 diabetes and hypertension. Diabetes Care 2014 Epub ahead of print]. doi:10.2337/dc14-1096

41. Schwedhelm E, Bartling A, Lenzen H, Tsikas D, Maas R, Brummer J, et al. Urinary 8iso-prostaglandin F2alpha as a risk marker in patients with coronary heart disease: a matched case-control study. Circulation. 2004;109(7):843-8.

42. Zinman B, Inzucchi SE, Lachin JM, Wanner C, Ferrari R, Fitchett D, et al. Rationale, design, and baseline characteristics of a randomized, placebo-controlled cardiovascular outcome trial of empagliflozin (EMPA-REG OUTCOME). Cardiovasc Diabetol. 2014;13:102.

\section{Submit your next manuscript to BioMed Central and take full advantage of:}

- Convenient online submission

- Thorough peer review

- No space constraints or color figure charges

- Immediate publication on acceptance

- Inclusion in PubMed, CAS, Scopus and Google Scholar

- Research which is freely available for redistribution 